\title{
Production optimization of flying fish roe analogs using calcium alginate hydrogel beads
}

\author{
Bom-Bi Ha', Eun-Hee Jo', Suengmok Cho ${ }^{2}$ and Seon-Bong Kim"
}

\begin{abstract}
Due to decreased supplies of marine resources and byproducts, new processing technologies for the development of analogs for natural fishery products are becoming increasingly important in the fishing industry. In the present study, we investigated the optimal processing conditions for flying fish roe analogs based on alginate hydrogels. Optimized processing of these analogs was performed by response surface methodology. The optimal processing conditions for the flying fish roe analogs (based on sphericity) were at a sodium alginate concentration of $2.41 \%$, calcium chloride solution curing time of $40.65 \mathrm{~min}$, calcium chloride concentration of $1.51 \%$, and a reactor stir speed of $254 \times g$. When the experiment was performed under these optimized conditions, the size (mm), sphericity (\%), and rupture strength ( $\mathrm{kPa}$ ) of the analogs were $2.2 \pm 0.12,98.2 \pm 0.2$, and $762 \pm 24.68$, respectively, indicating physical properties similar to their natural counterparts.
\end{abstract}

Keywords: Fish roe analogs, Analog food, Alginate hydrogel, Response surface methodology, Calcium alginate

Abbreviations: ANOVA, Analysis of variance; RSM, Response surface methodology; RSREG, Response surface regression; SAS, Statistical Analysis System

\section{Background}

Encapsulation technologies featuring alginate hydrogels have been widely applied to the bioprocessing of food, cosmetics, pharmaceuticals, and other biomaterials. Alginate, a gelling polymer, is composed of linear polymers of 1-4 linked $\beta$-D-mannuronic acid (M) and $\alpha$-L-guluronic acid (G) residues (Moe et al. 1995; Onsøyen 1997). In the presence of divalent cations such as $\mathrm{Ca}^{2+}$, alginate forms elastic hydrogels; the "egg-box" model has been adopted as a general description of alginate gel formation (Rousseau et al. 2004; Clark and Ross Murphy 1987). Alginate hydrogels have been used for the encapsulation of highly viscous high-fat food (Blandino et al. 1999), nutrients (Chen and Subirade 2006), bioactive components (Wichchukit et al. 2013), and probiotics (Subirade et al. 2010). In addition, they can protect acid-sensitive drugs from gastric fluids allowing for controlled drug

\footnotetext{
* Correspondence: owlkim@pknu.ac.kr

${ }^{1}$ Department of Food Science and Technology/Institute of Food Science, Pukyong National University, 45, Yongso-ro, Nam-gu, Busan 48513, South Korea

Full list of author information is available at the end of the article
}

release in the small intestine and are relevant to peptic ulcers (Hwang et al. 1993). Although there has been an increased number of applications of alginate hydrogels in biotechnology (Onsøyen 1996; Skjåk-bræk and Espevik 1996), studies on their use in food analogs is limited except when used as caviar (Ji et al. 2007a,b) and Cypselurus agoo roe analogs (Jo et al. 2014). Regarding the rheological characteristics of alginate hydrogels, their use in encapsulation may be a useful means of producing fish roe analogs.

Flying fish roe is one of the most consumed types of fish roes in Asia. Natural flying fish roe is widely used in sushi and for other culinary purposes in Korea and Japan. However, a consistent supply of these materials is difficult to secure due to abnormal climate changes and protective fishing policies of individual nations. Owing to this imbalance between supply and demand of these raw materials, there are limitations on their sustainable production. Therefore, the demand of suitable analogs is gradually increasing. It is also necessary to develop such analogs in order to eventually replace the natural 
materials, by establishing systemic processes and mass production techniques regardless of resource depletion.

In the present study, we optimize the processing conditions of these roe analogs using alginate hydrogels. The optimum conditions for production of the analogs were determined based on concentrations of sodium alginate and calcium chloride, sphericity, size, and rupture strength by using response surface methodology (RSM).

\section{Methods}

\section{Materials}

Sodium alginate and anhydrous calcium chloride (Junsei Chemical Co., Ltd., Japan) were used for gelation. All other chemicals and reagents used in this study were analytical grade.

\section{Production of flying fish roe analogs}

Flying fish roe analogs were produced using a technique first reported by Jo et al. (2014), with some modifications. A sodium alginate solution was prepared at different concentrations $(0.4-3.6 \%, w / v)$ and then dropped into $0.5-2.5 \%(w / v)$ calcium chloride at $0.06 \mathrm{~mL} / \mathrm{s}$ using a peristaltic pump (Cassette tube pump SMP-23, Eyela, Japan) with a single nozzle $\left(26 \mathrm{G} \times 1 / 2^{\prime \prime}\right)$ connected to a silicon tube. The stirring speed of calcium chloride solution in the reactor was set at $100-500 \times g$. The mixture was dropped every $2 \mathrm{~min}$ and cured for $0-60 \mathrm{~min}$ in solution to obtain the analogs. Afterwards, the analogs were collected with a strainer, then washed with deionized water, and stored at ambient temperature. The distance between the nozzle and the surface of the calcium chloride solution was $8 \mathrm{~cm}$.

\section{Size measurements}

Sizes were measured according to the method of Jo et al. (2014). An image analyzer (Image-Pro program) coupled to an optical microscope (Bx-50, Olympus, Japan) was used, with image analysis at $\times 40$ magnification. Five prepared analogs were randomly selected for each measurement and the average of their maximum and minimum diameters reported.

\section{Sphericity measurements}

Sphericity was measured according to the method of Jo et al. (2014) and expressed as the percent ratio of minimum diameter to maximum diameter obtained from size measurements of the analogs.

\section{Rupture strength measurement}

Rupture strengths were measured according to the method of Jo et al. (2014), using a rheometer (Model CR100D, Sun Scientific Co., Ltd., Japan) with the following conditions: round-disk stainless steel plunger $10 \mathrm{~mm}$ in diameter, $40 \mathrm{~mm} / \mathrm{min}$ penetration speed, adapter area of $0.79 \mathrm{~cm}^{2}$, sample-adapter distance of $5 \mathrm{~mm}$, and $1 \mathrm{kN}$ load-cell. Five samples were measured in each experiment.

\section{Experimental design}

Central composite design (CCD) was adopted in the optimization of flying fish roe analog processing. The CCD in this design consists of $2^{2}$ factorial points, four axial points $(\alpha=2)$, and three replicates of the central point (Tables 1 and 2). Concentrations of sodium alginate $\left(X_{1}, \%\right)$, curing time in calcium chloride solution $\left(X_{2}, \min \right)$, calcium chloride concentration $\left(X_{3}, \%\right)$, and calcium chloride solution stirring speed in the reactor $\left(X_{4}, \times g\right)$ were chosen as independent variables (IVs). The range and center point values of the four IVs were based on the results of preliminary experiments (Table 1). In order to prepare superior flying fish roe analogs in terms of external appearance, sphericity $\left(Y_{1}, \%\right)$ was used as the dependent variable (DV). Experimental runs were randomized in order to minimize the effects of unexpected variability in the observed responses.

\section{Data analysis}

The response surface methdology (RSREG procedure) of the MINITAB statistical software (Version 14, Minitab Inc., PA, USA) was used to fit the following secondorder polynomial:

$$
Y=\beta_{0}+\sum_{i=1}^{4} \beta_{i} X_{i}+\sum_{i=1}^{4} \beta_{i i} X_{i}^{2}+\sum_{i=1}^{3} \sum_{j=i+1}^{4} \beta_{i j} X_{i} X_{j}
$$

Here, $Y$ is the DV, $\beta_{0}$ is a constant, $\beta_{i}, \beta_{\mathrm{ii}}$, and $\beta_{\mathrm{ij}}$ are regression coefficients, and $X_{i}$ and $X_{j}$ are levels of the IVs. The response surface plots were developed using Maple software (Maple 7, Waterloo Maple Inc., Canada) and represent a function of two independent variables

Table 1 Experimental ranges and values of the independent variables in the central composite design for manufacturing process of the flying fish roe analogs

\begin{tabular}{|c|c|c|c|c|c|c|}
\hline \multirow[t]{2}{*}{ Independent variables (IVs) } & \multirow[t]{2}{*}{ Symbol } & \multicolumn{5}{|c|}{ Range and levels } \\
\hline & & -2 & -1 & 0 & +1 & +2 \\
\hline Sodium alginate concentration $(\%, w / v)$ & $x_{1}$ & 0.4 & 1.2 & 2 & 2.8 & 3.6 \\
\hline Curing time in calcium chloride solution (min) & $x_{2}$ & 0 & 15 & 30 & 45 & 60 \\
\hline Calcium chloride concentration $(\%, w / v)$ & $x_{3}$ & 0.5 & 1 & 1.5 & 2 & 2.5 \\
\hline Rotation speed of calcium chloride solution $(\times g)$ & $x_{4}$ & 100 & 200 & 300 & 400 & 500 \\
\hline
\end{tabular}


Table 2 Central composite design and responses of the dependent variables for the flying fish roe analogs processing to the independent variables

\begin{tabular}{|c|c|c|c|c|c|}
\hline \multirow[t]{2}{*}{ Run order } & \multicolumn{4}{|c|}{ Coded level } & \multirow{2}{*}{$\begin{array}{l}\text { Response } \\
Y_{1}\end{array}$} \\
\hline & $\overline{X_{1}}$ & $x_{2}$ & $x_{3}$ & $x_{4}$ & \\
\hline \multicolumn{6}{|c|}{ Factorial portion } \\
\hline 1 & -1 & -1 & -1 & -1 & 84.2 \\
\hline 2 & 1 & -1 & -1 & -1 & 91.7 \\
\hline 3 & -1 & 1 & -1 & -1 & 91.3 \\
\hline 4 & 1 & 1 & -1 & -1 & 95.5 \\
\hline 5 & -1 & -1 & 1 & -1 & 84.2 \\
\hline 6 & 1 & -1 & 1 & -1 & 92.0 \\
\hline 7 & -1 & 1 & 1 & -1 & 90.0 \\
\hline 8 & 1 & 1 & 1 & -1 & 95.5 \\
\hline 9 & -1 & -1 & -1 & 1 & 81.0 \\
\hline 10 & 1 & -1 & -1 & 1 & 91.7 \\
\hline 11 & -1 & 1 & -1 & 1 & 82.6 \\
\hline 12 & 1 & 1 & -1 & 1 & 91.7 \\
\hline 13 & -1 & -1 & 1 & 1 & 81.8 \\
\hline 14 & 1 & -1 & 1 & 1 & 94.4 \\
\hline 15 & -1 & 1 & 1 & 1 & 89.5 \\
\hline 16 & 1 & 1 & 1 & 1 & 95.2 \\
\hline \multicolumn{6}{|c|}{ Axial portion } \\
\hline 17 & -2 & 0 & 0 & 0 & 68.4 \\
\hline 18 & 2 & 0 & 0 & 0 & 95.5 \\
\hline 19 & 0 & -2 & 0 & 0 & 91.7 \\
\hline 20 & 0 & 2 & 0 & 0 & 94.7 \\
\hline 21 & 0 & 0 & -2 & 0 & 88.9 \\
\hline 22 & 0 & 0 & 2 & 0 & 85.7 \\
\hline 23 & 0 & 0 & 0 & 2 & 95.0 \\
\hline 24 & 0 & 0 & 0 & 2 & 86.4 \\
\hline \multicolumn{6}{|c|}{ Center portion } \\
\hline 25 & 0 & 0 & 0 & 0 & 97.5 \\
\hline 26 & 0 & 0 & 0 & 0 & 98.2 \\
\hline 27 & 0 & 0 & 0 & 0 & 97.7 \\
\hline
\end{tabular}

$Y$ (sphericity, \%), $X_{1}$ (sodium alginate concentration, \%), $X_{2}$ (curing time in calcium chloride solution, $\mathrm{min}$ ), $X_{3}$ (calcium chloride concentration, \%), $X_{4}$ (rotation speed of calcium chloride solution, $\times g$ )

while keeping the other two independent variables at their optimal values.

\section{Statistical analysis}

All the results were conducted to analysis of variance at a level of $P<0.05$, and the means were set apart using Duncan's multiple range tests $(\alpha=0.05)$. The analysis of data was subjected through the RSREG procedure of SAS software.

\section{Results and discussion}

Optimization for the production of the analogs using RSM

Process optimization was used to determine the conditions needed to obtain analogs most closely resembling natural ones. Sphericity, which indicates the degree of similarity between the analogs and a sphere, was defined as the ratio of minimum diameter to maximum diameter of the prepared analogs. The most important factors affecting sphericity $(Y$, sphericity, \%) were determined in the preliminary study, with the central point and ranges determined by CCD (Box and Wilson 1951). The independent variables and central point in the analog production were the sodium alginate concentration $(2 \%, w / v)$, curing time in calcium chloride solution (30 min), calcium chloride concentration $(1.5 \%, w / v)$, and stir speed of calcium chloride in the reactor $(300 \times g)$ (Table 1$)$. A total of 27 intervals were included in the experiment, and sphericity results of the analogs prepared in each interval are shown in Table 2. RSM was performed using the data obtained by the RSREG procedure of SAS software. Based on these results, the statistical significance each associated with the linear term $\left(X_{1}, X_{2}, X_{3}, X_{4}\right)$, quadratic term $\left(X_{1} X_{1}, X_{2} X_{2}\right.$, $\left.X_{3} X_{3}, X_{4} X_{4}\right)$, and interaction term was determined by $\mathrm{t}$ statistics. Furthermore, the statistical significance of the second-order polynomial model was measured using the estimated coefficient of each model as well as analysis of variance (ANOVA) (Table 3). For the linear coefficient, $X_{1}(P<0.001)$ and $X_{4}(P=0.0254)$ exhibited statistical significance at $P<0.05$ but $X_{2}(P=0.0175)$ and $X_{3}(P=0.6162)$ did not show any statistical significance.

For the quadratic coefficient, there was statistical significance found in $X_{1} X_{1}(P<0.001), X_{3} X_{3} \quad(P=0.001)$, and $X_{4} X_{4}(P=0.020)$, but not $X_{2} X_{2}(P=0.133)$. For the interaction coefficient, no significance was exhibited in $X_{1} X_{2} \quad(P=0.217), \quad X_{1} X_{3} \quad(P=0.993), X_{1} X_{4} \quad(P=0.249)$, $X_{2} X_{3}(P=0.633), X_{2} X_{4}(P=0.369)$, and $X_{3} X_{4}(P=0.194)$. In order to develop fitted response surface model equations, all insignificant terms $(P>0.05)$ were eliminated and the resulting fitted models are shown in Table 4. The coefficient of determination in the polynomial $R^{2}$ was 0.924 at $P=0.000$. Such a high coefficient of determination and significance arise from experimental conditions designed by preliminary studies. ANOVA was employed to evaluate the statistical significance of the second-order polynomial model, and ANOVA based on the dependent variables was applied to express a $Y$ (sphericity, \%) response model. In the ANOVA results, all linear terms $(P<0.001)$ and quadratic terms $(P<0.001)$, except the cross-product term $(P=0.453)$, had probabilities $>99 \%$ (Table 5). CCD was used to identify the optimum sphericity conditions in the prepared analogs. In preliminary studies, the optimum ranges of sodium alginate concentration $\left(X_{1}, 2 \%\right)$, curing time in calcium chloride solution 
Table 3 Estimated coefficients of the fitted quadratic polynomial equation for different responses based on t-statistic

\begin{tabular}{ccc}
\hline Parameter & $Y($ sphericity, \%) & \\
\cline { 2 - 3 } & Coefficient & $P$ value \\
\hline Constant & 97.80 & 0.000 \\
$X_{1}$ & 4.89 & 0.000 \\
$X_{2}$ & 1.51 & 0.018 \\
$X_{3}$ & 0.27 & 0.633 \\
$X_{4}$ & -1.40 & 0.026 \\
$X_{1} X_{1}$ & -3.76 & 0.000 \\
$X_{2} X_{2}$ & -0.94 & 0.133 \\
$X_{3} X_{3}$ & -2.42 & 0.001 \\
$X_{4} X_{4}$ & -1.57 & 0.020 \\
$X_{1} X_{2}$ & -0.88 & 0.217 \\
$X_{1} X_{3}$ & 0.01 & 0.993 \\
$X_{1} X_{4}$ & 0.82 & 0.249 \\
$X_{2} X_{3}$ & 0.33 & 0.633 \\
$X_{2} X_{4}$ & -0.63 & 0.369 \\
$X_{3} X_{4}$ & 0.93 & 0.194 \\
\hline$Y\left(5 X_{1}\right.$ & &
\end{tabular}

$Y$ (sphericity, \%), $X_{1}$ (sodium alginate concentration, \%), $X_{2}$ (curing time in calcium chloride solution, $\mathrm{min}$ ), $X_{3}$ (calcium chloride concentration, \%), $X_{4}$ (rotation speed of calcium chloride, $\times g$ )

$\left(X_{2}, 30 \mathrm{~min}\right)$, calcium chloride concentration $\left(X_{3}, 1.5 \%\right)$, and stirring speed of the calcium chloride solution in the reactor $\left(X_{4}, 300 \times g\right)$ were determined (Table 1$)$. RSREG resulted in saddle points having eigenvalues that show positive and negative values. Additionally, the optimum conditions (coded values) of the analogs based on RSM were $0.51 \%$ for the sodium alginate concentration $\left(X_{1}\right)$, $0.71 \mathrm{~min}$ for the calcium chloride solution curing time $\left(X_{2}\right), 0.02 \%$ for calcium chloride concentration $\left(X_{3}\right)$, and $-0.46 \times g$ for the calcium chloride solution stirring speed $\left(X_{4}\right)$. When these results were substituted into

Table 4 Analysis of variance (ANOVA) for response of dependent variables

\begin{tabular}{|c|c|c|c|c|c|c|c|}
\hline Response & Source & & DF & SS & MS & $F$ value & $P$ value \\
\hline \multirow[t]{8}{*}{ Y } & \multirow[t]{4}{*}{ Regression } & Linear & 4 & 677.288 & 169.322 & 23.15 & 0.000 \\
\hline & & Quadratic & 4 & 343.637 & 85.909 & 11.74 & 0.000 \\
\hline & & Cross-product & 6 & 45.159 & 7.526 & 1.03 & 0.453 \\
\hline & & Total model & 14 & 1066.084 & 76.149 & 10.41 & 0.000 \\
\hline & \multirow[t]{3}{*}{ Residual } & Lack of fit & 10 & 87.527 & 8.753 & 67.33 & 0.015 \\
\hline & & Pure error & 2 & 0.260 & 0.130 & & \\
\hline & & Total error & 12 & 87.787 & 7.316 & & \\
\hline & Total & & 26 & 1153.87 & & & \\
\hline
\end{tabular}

DF degrees of freedom, SS sum of square, MS mean square equation (1), $X_{1}, X_{2}, X_{3}$, and the uncoded value of $X_{4}$ were $2.41 \%, 40.65 \mathrm{~min}, 1.51 \%$, and $254 \times g$, respectively. When the experiment was carried out with the uncoded values as calculated above, the expected sphericity (Y, \%) of the analogs was $99.9 \%$ compared to an experimental value of $98.2 \%$, representing minimal difference (Table 6).

In general, alginates undergo gelling to yield hydrogels in the presence of metallic divalent cations (Smidsrød and Haug 1972; Grant et al. 1973); for example, calcium ions make stronger alginate gels than potassium and sodium ions (Montero and PerezMateos 2002). When alginate solutions are added into calcium chloride solutions, calcium ions bind to the carboxylic groups of G-block alginate molecules to yield alginate gels (Moe et al. 1995; Sabraa 2005). However, M-block rich alginates have weak binding with calcium and form more elastic gels (Sabraa 2005). Alginates with high $M / G$ ratios produce beads with smaller sizes than in the case of low $\mathrm{M} / \mathrm{G}$ ratio alginate beads (Kendal Jr. et al. 2004; Mørch et al. 2006), as alginates of lower M/G ratio form more porous gels (Simpson et al. 2003). Curing of alginate gels in calcium chloride solution is promoted by increased calcium concentration, which benefits the sphericity and physical strength of the gels.

\section{Response surface plots and impact factors}

Figure 1 shows a three-dimensional graph describing the effects of the independent variables $\left(X_{1}, X_{2}\right.$, $X_{3}, X_{4}$ ) on the dependent variable $(Y)$ using Maple software. Among the different analog production processes, the present study focused on the effects of sodium alginate concentration $\left(X_{1}, \%\right)$, curing time in calcium chloride solution $\left(X_{2}, \mathrm{~min}\right)$, calcium chloride concentration $\left(X_{3}, \%\right)$, and calcium chloride solution stirring speed in the reactor $\left(X_{4}, \times g\right)$ as key factors in analog production. The graph represents the correlation between $X_{1}, X_{2}, X_{3}$, and $X_{4}$. All response surface graphs indicate that the sphericity of the analogs increased as the coded values of IVs approached zero. In particular, the sphericity of the analogs (DV) decreased remarkably as $X_{1}$ approached -2 . On the other hand, $X_{2}$ was not considerably influential on the sphericity of the analogs compared to the other independent variables. Therefore, based on Fig. 1, all independent variables except for the curing time in calcium chloride solution influenced the sphericity of the analogs, and the concentration of sodium alginate played an especially important role. Jo et al. (2014) described the effects of heat, salt, and hydrocolloids on analog formation, and Ji et al. (2007a,b) made caviar analogs using calcium alginate gel capsules. The shape transition of the Ca-alginate beads was 
Table 5 Optimal conditions for the flying fish roe analogs manufacturing process from sodium alginate

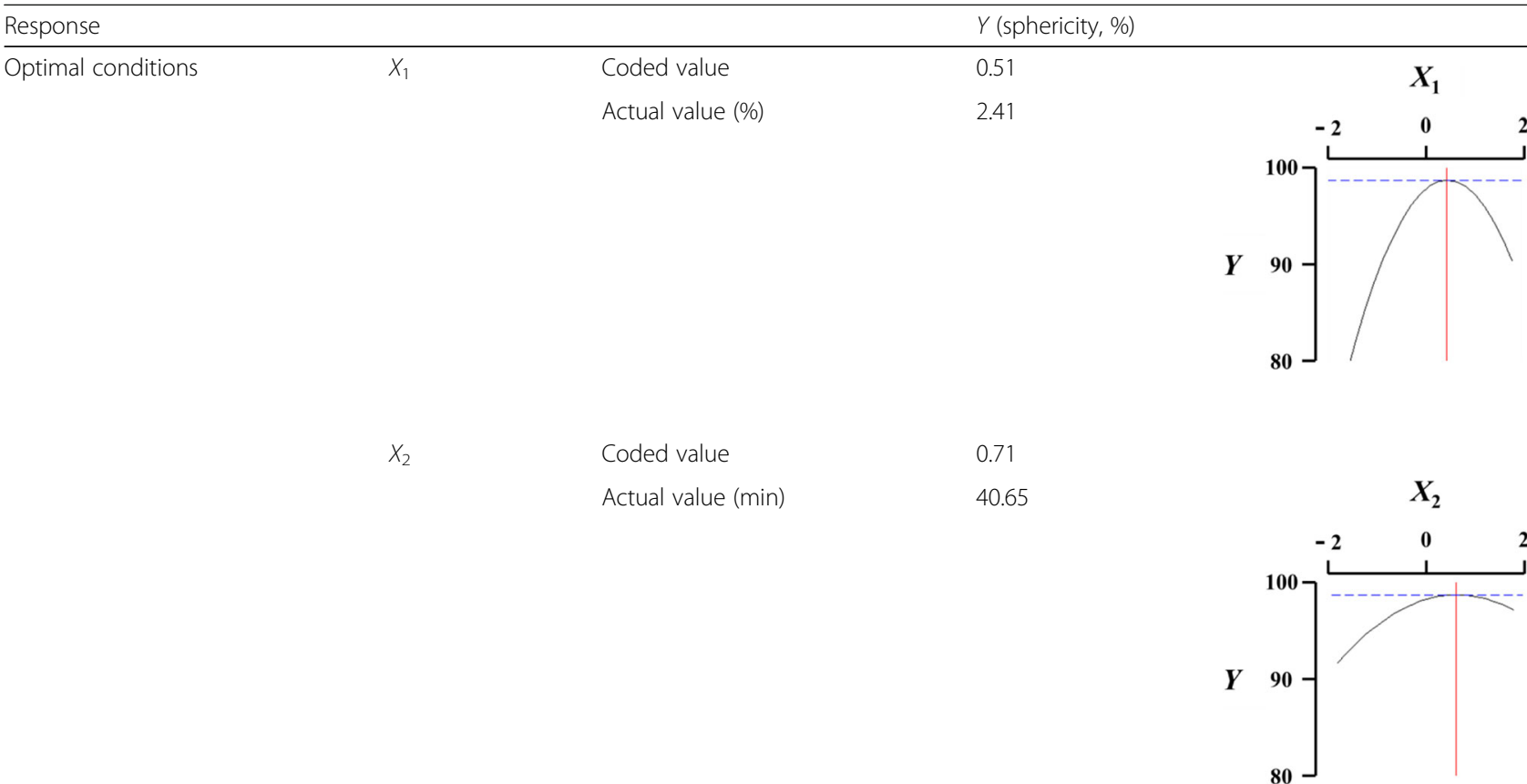

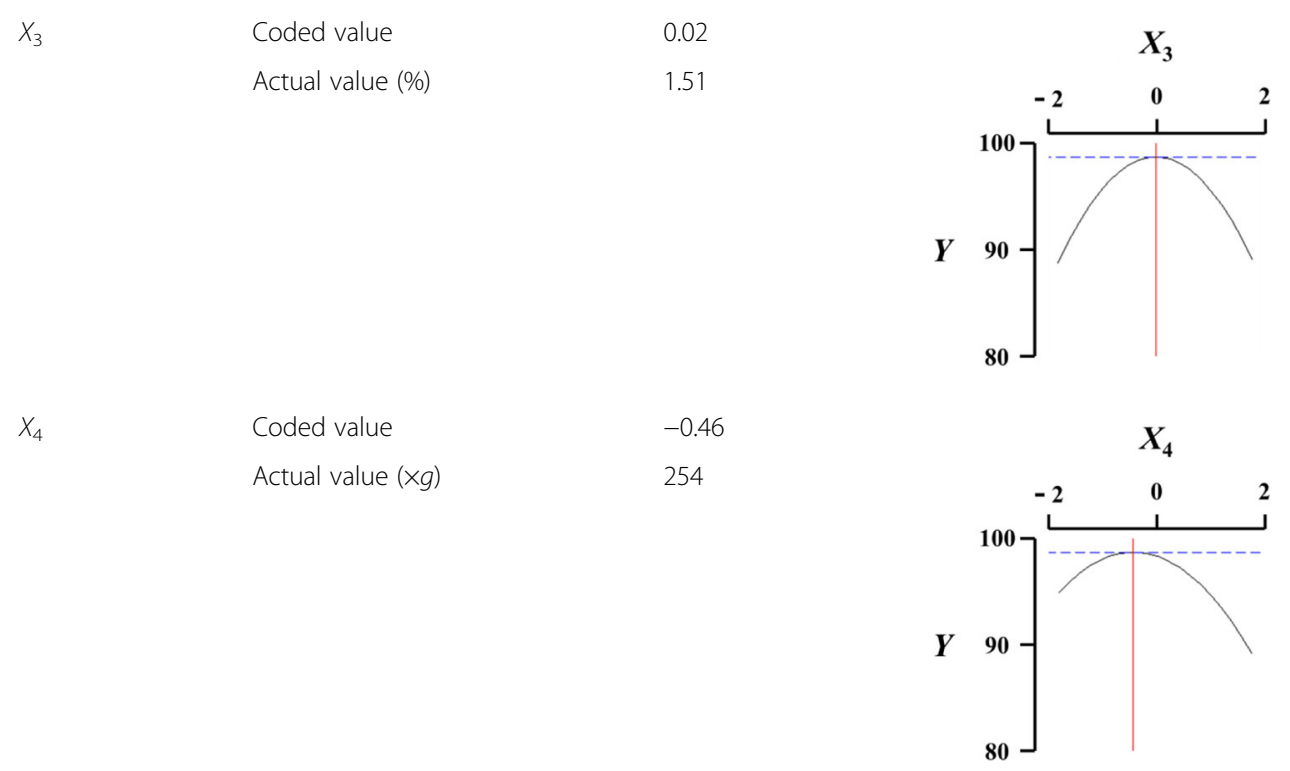

Stationary point

Predicted value of response $Y$

Experimental value of response $Y$
Saddle point

99.9

98.2

$X_{1}$ (sodium alginate concentration, \%), $X_{2}$ (curing time in calcium chloride solution, min), $X_{3}$ (calcium chloride concentration, \%), $X_{4}$ (rotation speed of calcium chloride, $\times g$ )

distinguished into three phases based on collection distance and was affected by the combined influence of the solution properties, the collection distance and the drop size (Chan et al. 2009).

\section{Conclusions}

Demand for analogs of crab meat and caviar food is gradually increasing, due to recent abnormal climate issues and fishery policy changes. Thus, improved 
Table 6 Comparison of physical properties of natural flying fish roe and the analogs manufactured using the optimal processing condition

\begin{tabular}{lll}
\hline Factors & Flying fish roe analogs & Natural flying fish roe \\
\hline Size $(\mathrm{mm})$ & $2.2 \pm 0.12^{\mathrm{b}}$ & $1.88 \pm 0.02^{\mathrm{a}}$ \\
Sphericity (\%) & $98.2 \pm 0.2^{\mathrm{a}}$ & $98.19 \pm 1.55^{\mathrm{a}}$ \\
Rupture strength (kPa) & $762 \pm 24.68^{\mathrm{a}}$ & $803.6 \pm 126.37^{\mathrm{a}}$ \\
\hline
\end{tabular}

The same superscripts in a raw are not significantly different each other at $P<0.05$ development of such analogs is essential to substitute for natural products. Alginate was adopted for the production of flying fish roe analogs in this study because it easily forms gels and is easy to handle, non-toxic to humans, and inexpensive. The study elucidated the production of flying fish roe analogs under optimized conditions using RSM. The optimum conditions were $2.41 \%$ sodium alginate concentration, 40.65 min curing time in calcium chloride solution, $1.51 \%$ calcium chloride concentration, and a $254 \times g$ stirring speed of the calcium chloride solution in the reactor. When performed at these optimum conditions, this process yielded a high sphericity of $98.2 \%$. The size (mm),

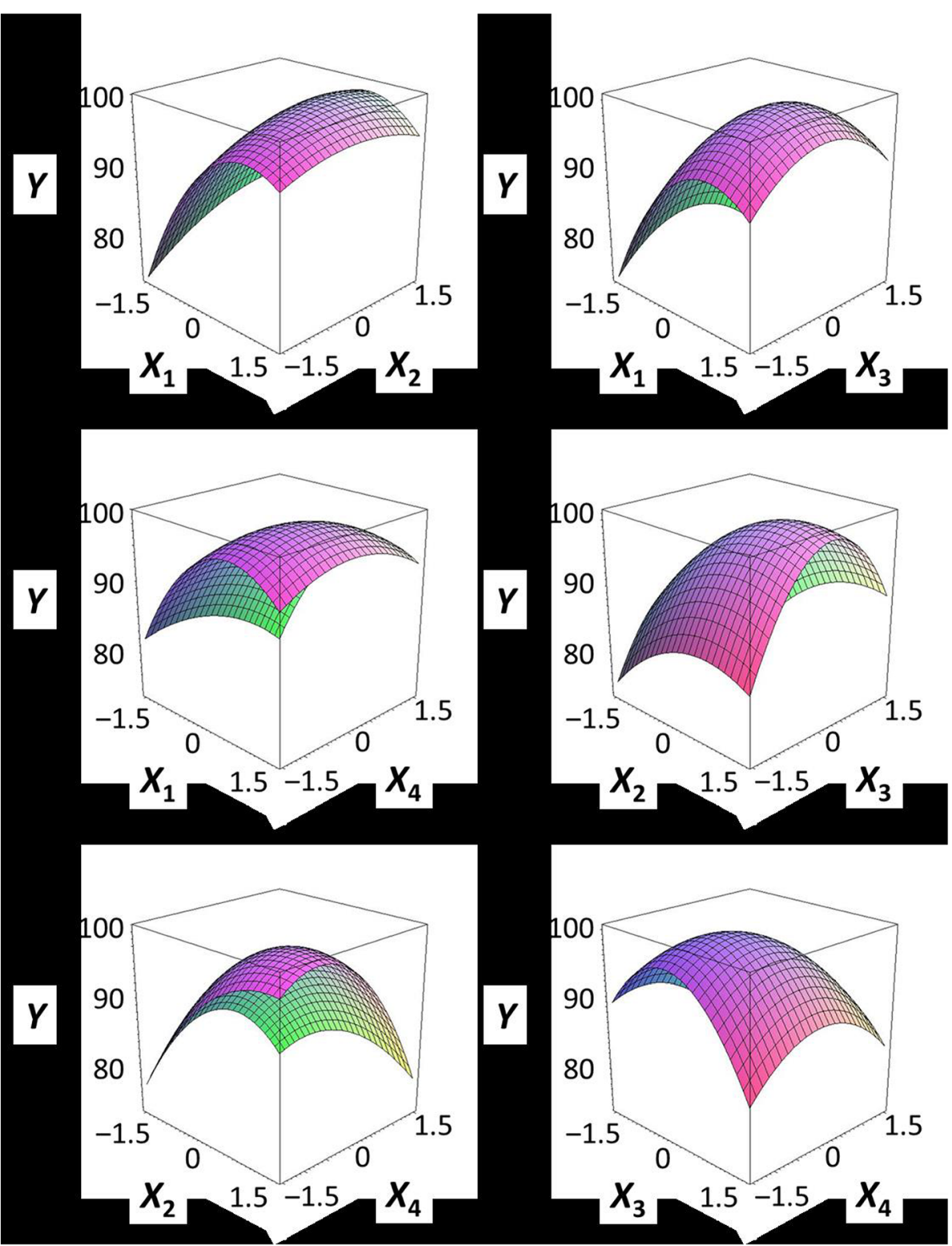

Fig. 1 Response surface plots for flying fish roe analogs manufacturing process from sodium alginate and calcium chloride. $Y\left(\right.$ sphericity, \%), $X_{1}$ (sodium alginate concentration, \%), $X_{2}$ (curing time in calcium chloride solution, min), $X_{3}$ (calcium chloride concentration, \%), $X_{4}$ (rotation speed of calcium chloride, $\times g$ ) 
sphericity (\%), and rupture strength ( $\mathrm{kPa}$ ) of the analogs produced using these optimum conditions were $2.2 \pm 0.12$, $98.2 \pm 0.2$, and $762 \pm 24.68$, respectively; these physical properties are quite similar to those of natural roe. With subsequent improvements to palatability and mass production, these roe analogs may be viable substitutes for natural roe.

\section{Funding}

This work was supported by a Research Grant of Pukyong National University (2016)

\section{Availability of data and materials}

The datasets supporting the conclusions of this article are included within the article. There is no additional data and materials to disclose.

\section{Authors' contributions}

$\mathrm{B}-\mathrm{BH}$ and $\mathrm{E}-\mathrm{HJ}$ carried out the preparation of the analogs and measurement of size, sphericity, and rupture strength. B-BH and S-MC carried out the RSM design using SAS system (Version 9.01, SAS Institute Inc., USA) and Maple software (Maple 7. Waterloo Maple Inc., Canada). B-BH and S-BK conceived of the study and participated in its design and coordination and helped to draft the manuscript. All authors read and approved the final manuscript.

\section{Competing interests}

The authors declare that they have no competing interests.

\section{Consent for publication}

Not applicable.

\section{Ethics approval and consent to participate}

Not applicable.

\section{Author details}

'Department of Food Science and Technology/Institute of Food Science, Pukyong National University, 45, Yongso-ro, Nam-gu, Busan 48513, South Korea. ${ }^{2}$ Research Group of Innovative Functional Foods, Korea Food Research Institute, Seongnam 13539, South Korea.

\section{Received: 8 June 2016 Accepted: 24 August 2016}

\section{Published online: 09 September 2016}

\section{References}

Blandino A, Macias M, Cantero D. Formation of calcium alginate gel capsules: influence of sodium alginate and $\mathrm{CaCl}_{2}$ concentration on gelation kinetics. J Biosci Bioengin. 1999;88:686-89.

Box GEP, Wilson KB. On the experimental attainment of optimum conditions. J Royal Stat Soc (Ser B). 1951;13:1-45.

Chan ES, Lee BB, Ravindra P, Poncelet D. Prediction models for shape and size of Ca-alginate macrobeads produced through extrusion-dipping method. J Colloid Interf Sci. 2009:338:63-72.

Chen LY, Subirade M. Effect of preparation conditions on the nutrient release properties of alginate-whey protein granular microspheres. Eur J Pharm Biopharm. 2006;65:354-62.

Clark AH, Ross Murphy SB. Structural and mechanical properties of biopolymer gels. Adv Polym Sci. 1987;83:57-192

Grant GT, Morris ER, Rees DA, Smith JC, Thom D. Biological interactions between polysaccharides and divalent cations: the egg-box model. FEBS Let. 1973:32:195-98.

Hwang SJ, Rhee GJ, Jo HB, Lee KM, Kim CK. Alginate beads as controlled release polymeric drug delivery system. J Korean Pharm Sci. 1993;23:19-26.

$\mathrm{Ji} \mathrm{Cl}$, Cho SM, GU YS and Kim SB. The processing optimization of caviar analogs encapsulated by calcium-alginate gel membranes. Food Sci Biotechnol. 2007a; 16:557-64.

Ji Cl, Cho SM, Yoon YS, Kim SB. Optimization of physical conditions for caviar analog preparation using calcium-alginate gel capsules. J Fish Sci Technol. 2007b;10:103-12.
Jo EH, Ha BB, Kim SB. Effects of Heat, Salt and hydrocolloid treatments on flying fish Cypselurus agoo roe analogs prepared using calcium alginate hydrogels. J Fish Aquat Sci. 2014;17:203-7.

Kendall Jr WF, Darrabie MD, El-shewy HM, Opara EC. Effect of alginate composition and purity on alginate microspheres. J Microencap. 2004;21:821-28.

Moe ST, Draget Kl, Skjåk-bræk G, Smidsrød O. Alginates. In: Food polysaccharides and their applications, vol. 9. New York: Marcel Dekker; 1995. p. 245-86.

Montero P, Perez-mateos M. Effects of $\mathrm{Na}^{+}, \mathrm{K}^{+}$, and $\mathrm{Ca}^{2+}$ on gels formed from fish mince containing a carrageenan or alginate. Food Hydrocolloids. 2002;16:375-82.

Mørch YA, Donati I, Strand BL, Skjåk-bræk G. Effect of $\mathrm{Ca}^{2+}, \mathrm{Ba}^{2+}$, and $\mathrm{Sr}^{2+}$ on alginate microbeads. Biomacromol. 2006;7:1471-80.

Onsøyen E. Commercial applications of alginates. Carbohydr Eur. 1996;14:26-31.

Onsøyen E. Alginates. In A. Imeson (Ed.). Thickening and gelling agents for food. London: Blackie Academic \& Professional; 1997. p. 22-24.

Rousseau I, Le cerf D, Picton L, Argillier JF, Muller G. Entrapment and release of sodium polystyrene sulfonate (SPS) from calcium alginate gel beads. Eur Polym J. 2004;40:2709-15.

Sabraa W. Alginate: a polysaccharide of industrial interest and diverse biological functions. In: Polysaccarides: structural diversity and functional versatility. 2nd ed. New York: Marcel dekker; 2005. p. 515-33.

Skjåk-bræk G, Espevik T. Application of alginate gels in biotechnology and biomedicine. Carbohydr Eur. 1996;14:19-25.

Simpson NE, Grant SC, Blackband SJ, Constantinidis I. NMR properties of alginate microbeads. Biomater. 2003;24:4941-48.

Smidsrød O, Haug A. Dependence upon gel-sol state of the ion-exchange properties of alginates. Acta Chem Scand. 1972;26:2063-74.

Subirade M, Hebrand G, Hoffart V, Beyssac E, Cardoy JM, Alic M. Coated whey protein/alginate microparticles as oral controlled delivery systems for probiotic yeast. J Microencap. 2010;27:292-302.

Wichchukit S, Oztop MH, Mccarthy MJ, Mccarthy KL. Whey protein/alginate beads as carries of a bioactive component. Food Hydrocolloids. 2013;33:66-73.

\section{Submit your next manuscript to BioMed Central} and we will help you at every step:

- We accept pre-submission inquiries

- Our selector tool helps you to find the most relevant journal

- We provide round the clock customer support

- Convenient online submission

- Thorough peer review

- Inclusion in PubMed and all major indexing services

- Maximum visibility for your research

Submit your manuscript at www.biomedcentral.com/submit
) Biomed Central 